\title{
Neuroleptic Drug Exposure and Incidence of Tardive Dyskinesia: A Records-based Case-Control Study
}

\author{
DONNA L. MARSHALL, PharmD, MS; THOMAS K. HAZLET, PharmD, DrPH; \\ JACQUELINE S. GARDNER, PhD; and DAVID K. BLOUGH, PhD
}

\begin{abstract}
BACKGROUND: With the introduction of atypical neuroleptic medications into the marketplace, the use of conventional neuroleptics has fallen, attendant with the perception of a more favorable side-effect profile for the atypical neuroleptics.

OBJECTIVE: The purpose of this study was to determine the risk of tardive dyskinesia (TD) associated with atypical and conventional neuroleptics.

METHODS: Subjects were adult users of the Veterans Administration Puget Sound Health Care System (VA-PSHCS) who received $\geq 1$ prescription for neuroleptic medications during the study period. Electronic medical and pharmacy records were used to obtain neuroleptic drug exposure, exclusionary diagnosis, diagnosis for TD, and select demographic data. Medical records were reviewed to collect demographic data not available electronically. Controls were randomly selected from a cohort of neuroleptic users without TD. The case-defining event was the diagnosis of TD.
\end{abstract}

RESULTS: There were 42 cases and 160 controls for the final analysis. The only demographic difference found was a higher proportion of Caucasians (90\%) in the TD group compared to the control group $(76 \%)$. There was no significant difference in the risk of TD for patients on conventional neuroleptics compared to the atypical neuroleptic users ( $\mathrm{OR}=1.29 ; 95 \% \mathrm{Cl}=0.71-2.34$ ). After adjusting for age, gender, race, schizophrenia, schizoaffective disorder, depression, and anti-Parkinson drugs, there was still no significant difference in risk of TD between cases and controls $(\mathrm{OR}=1.02$; $95 \% \mathrm{Cl}=0.465-2.232$ ).

CONCLUSION: This study did not find a statistically significant difference in the risk of TD for users of conventional neuroleptics versus users of atypical neuroleptics.

KEYWORDS: Antipsychotic agents, Adverse events, Dyskinesia, Drug Induced, Casecontrol study

J Man Care Pharm 2002:(8)4:259-65

\section{Authors}

DONNA L. MARSHALL, PharmD, MS, is President, Marshall RX Consultants, Inc., Renton, Washington; THOMAS K. HAZLET, PharmD, DrPH, is Associate Professor, University of Washington, Department of Pharmacy, Seattle, Washington; JACQUELINE S. GARDNER, PhD, is Associate Professor, University of Washington, Department of Pharmacy, Seattle, Washington; DAVID K. BLOUGH, PhD, is Clinical Associate Professor, University of Washington, Department of Pharmacy, Seattle, Washington.

AUTHOR CORRESPONDENCE: Donna L. Marshall, PharmD, MS, Marshall RX Consultants, Inc., 18601 173rd Way S.E., Renton, WA 98058. Tel: (425) 2541140; Fax: (425) 228-2399; E-mail: donnamarshall@qwest.net

Copyright $\bigcirc 2002$ Academy of Managed Care Pharmacy. All rights reserved.
$\mathrm{T}$ ardive dyskinesia (TD) is a potentially irreversible disorder characterized by aimless, uncontrollable movements. These movements typically involve the tongue, jaw, trunk, and extremities. Tardive dyskinesia usually develops after chronic exposure (more than 3 months) to neuroleptic medication or, within 4 weeks of discontinuing an oral neuroleptic medication (8 weeks of a depot neuroleptic). ${ }^{1}$ The specific mechanism involved in tardive dyskinesia remains unclear, although supersensitivity of dopaminergic receptors may be responsible. ${ }^{2}$ Studies suggest the prevalence of tardive dyskinesia is $15 \%$ to $20 \%$ in patients receiving neuroleptic medication and $1 \%$ to $5 \%$ in individuals not receiving neuroleptic medication. The use of neuroleptic medications results in a 3\% to 5\% incidence of tardive dyskinesia per year. ${ }^{1}$

Several risk factors have been associated with a higher incidence of tardive dyskinesia. Among them are increasing age, female gender, and dose and duration of neuroleptic exposure. The prevalence of tardive dyskinesia increases with age. In patients younger than 40 years, the prevalence of tardive dyskinesia is $5 \%$ to $10 \%$ and increases to $50 \%$ to $70 \%$ in patients older than 65 years. ${ }^{3}$ The risk of tardive dyskinesia is similar in young men and women. However, it occurs more often in elderly women than in elderly men. ${ }^{1,4}$

Psychiatric diagnosis has also been shown to be related to the risk of tardive dyskinesia. It has been found that schizophrenic patients appear to have a lower risk of tardive dyskinesia, while patients with schizoaffective disorder appear to be at greater risk for developing tardive dyskinesia.. ${ }^{4}$ Mood disorders, such as depression and bipolar disorder, have also been associated with a higher risk of tardive dyskinesia. ${ }^{4}$ Other diseases that have been associated with an increased risk of tardive dyskinesia include diabetes mellitus and organic brain dysfunction. Ganzini found that the prevalence of tardive dyskinesia was significantly higher in diabetic subjects than their nondiabetic matched controls.'

Drugs other than neuroleptic medications that have the potential to block dopamine receptors may also lead to tardive dyskinesia with prolonged use. These drugs include the gastrointestinal prokinetic drug metoclopramide, the antidepressant amoxapine, and drugs for the treatment of Parkinson's disease such as bromocriptine, pergolide, and levodopa/carbidopa. ${ }^{4}$ Prolonged amphetamine or stimulant abuse can also cause a syndrome similar to tardive dyskinesia. Antimalarial medications that are chloroquine-based and oral contraceptives also have the potential to cause dyskinesias with chronic use. ${ }^{1}$ Recently, the selective serotonin-reuptake inhibitors have also been shown to cause movement disorders. ${ }^{6}$ 


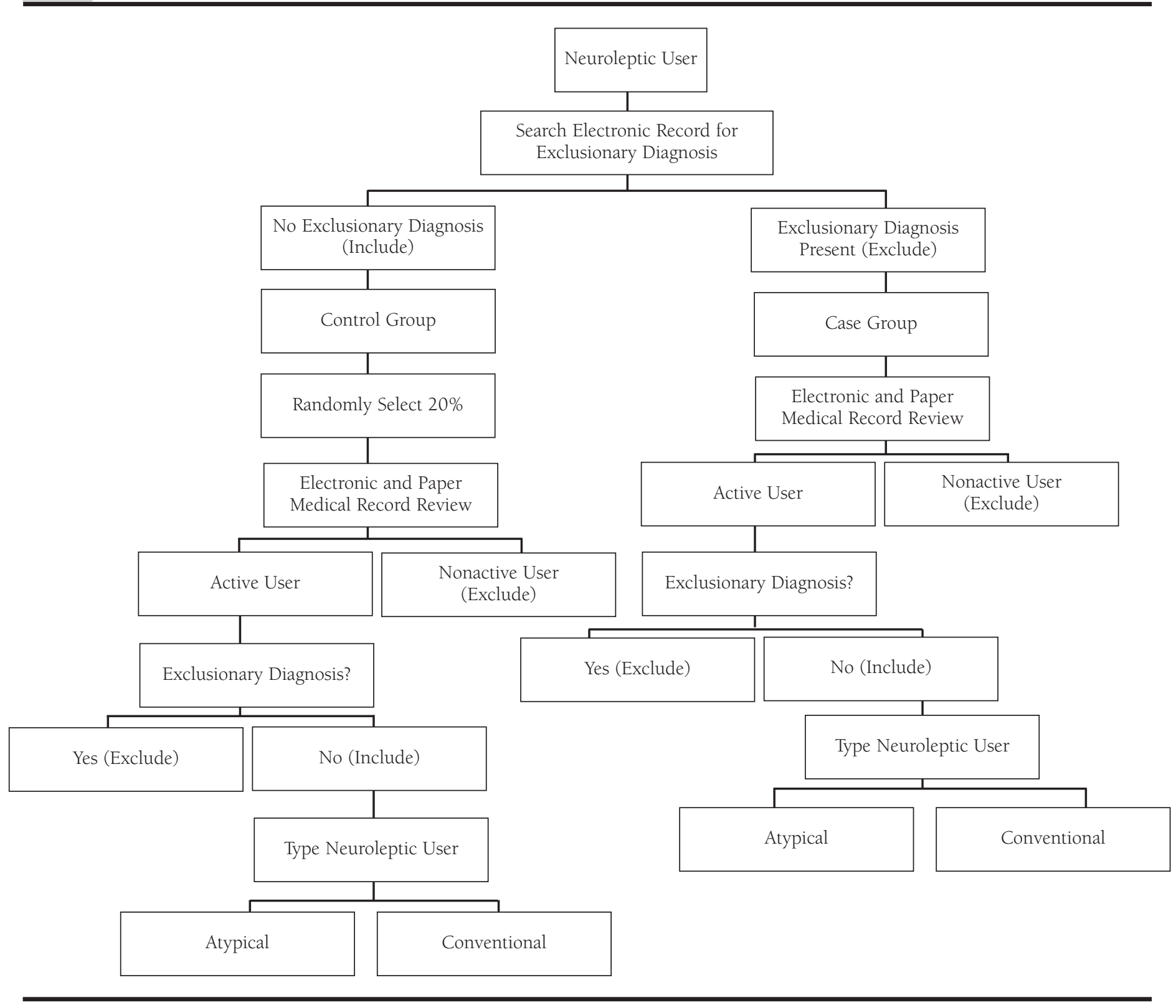

Neuroleptic or antipsychotic medications such as haloperidol and chlorpromazine have been the mainstay for treatment of schizophrenia and other psychotic disorders for many years. The use of these medications does not come without risks. Neuroleptic medications are reported to cause tardive dyskinesia. More recent market introductions of neuroleptic medications belong to a class of drugs dubbed "atypical" due to their unique mechanism of action. Clozapine was introduced to the United States market in
1989, risperidone in 1993, olanzepine in 1996, quetiapine in 1997, and ziprasidone in 2001. ${ }^{7}$ It has been suggested that these atypical neuroleptics have a lower incidence of tardive dyskinesia compared to the conventional neuroleptics. Although there is some evidence that the atypical medications may have a decreased occurrence of tardive dyskinesia, reports of tardive dyskinesia associated with use of these new atypical neuroleptics have appeared in the literature..$^{8-18}$ 
The newer, atypical neuroleptics on average cost 20 times more per day of therapy than the conventional neuroleptics. Managed care organizations have an interest in determining the value-formoney equation for the atypical neuroleptics. Jeste proposes that this additional cost has been a deterrent to managed care organizations in the prescribing of atypical medications. ${ }^{19}$ Cost concerns need to be balanced against the risk of potentially serious side effects, especially tardive dyskinesia. Due to the conflicting findings in the literature, the question of whether one drug or a particular class of drugs is associated with a higher risk of tardive dyskinesia remains unanswered. This study examines the difference in risk of tardive dyskinesia associated with the newer, atypical neuroleptic medications compared to the older, conventional neuroleptic medications.

\section{Methods}

\section{Subject Selection}

This study was a records-based, nested, case-control study of the association between neuroleptic drug use and tardive dyskinesia in a cohort of neuroleptic users at the Veterans Administration Puget Sound Health Care System (VA-PSHCS) between January 1, 1996, and December 31, 1998. The study protocol was approved by the Institutional Review Boards of both the VA-PSHCS and the University of Washington. Electronic pharmacy data were used to identify neuroleptic users and to capture all prescription drugs used by the cohort during the study period (Figure 1).

Study subjects were active adult ( $>21$ years of age) users of the VA-PSHCS who had received more than one prescription for a neuroleptic medication during the study period. Within this study, the case-defining event was the diagnosis of tardive dyskinesia. Diagnosis of tardive dyskinesia was defined as the presence of the ICD-9 code 333.82 in any hospital discharge diagnosis or clinic visit diagnosis for each subject during the study period. Electronic encounter data were used to identify those subjects with a diagnosis of tardive dyskinesia. Controls were selected at random, using the SPSS 8.0 biostatistical software, ${ }^{20}$ from the cohort of neuroleptic users without a diagnosis for tardive dyskinesia. To ensure subjects were active users of the VA-PSHCS, all subjects were required to have had more than one encounter with the VAPSHCS in the period 90 days prior to the first prescription of a neuroleptic medication and in the period 90 days after the last prescription-fill of a neuroleptic medication, or September 30, 1998, whichever came first.

Subjects receiving risperidone, olanzapine, quetiapine, or clozapine at any time during the study period were considered users of atypical neuroleptics. Ziprasidone was not available in the U.S. market at the time of this study. Subjects receiving any one of the remaining neuroleptics listed in Table 1 were considered users of conventional neuroleptics. Atypical neuroleptic users were followed from study entry until either (a) they were switched to a

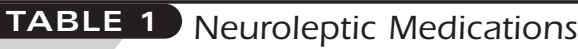

\section{Conventional Neuroleptic Medications}

acetophenazine maleate

chlorpromazine $\mathrm{HCl}$

chlorprothixene

fluphenazine

haloperidol

loxapine

mesoridazine besylate

perphenazine

pimozide

prochlorperazine

thioridazine $\mathrm{HCl}$

thiothixene

trifluoperazine $\mathrm{HCl}$

molindone $\mathrm{HCl}$

\begin{tabular}{l}
\hline Atypical Neuroleptic Medications \\
\hline clozapine \\
olanzapine \\
quetiapine \\
risperidone \\
\hline
\end{tabular}

\section{TABLE 2 Data-Collection Elements}

\begin{tabular}{ll}
\hline Data Element & Categories \\
\hline Psychiatric disease & - schizophrenia \\
& - post-traumatic stress disorder \\
& - depressic brain dysfunction \\
& - bipolar disorder \\
& - schizoaffective disorder \\
& - psychosis not otherwise specified \\
\hline - gender & - race (Caucasian, African American, \\
& Hispanic, Asian/Pacific Islander, \\
& Native American) \\
& - date of birth
\end{tabular}

Other medications that may

cause tardive dyskinesia

sertraline, fluoxetine, metoclopramide, amoxapine, oral contraceptives, chloroquine phosphate, hydroxychloroquine sulfate, primaquine phosphate

\begin{tabular}{ll}
\hline Anti-Parkinson medication & $\begin{array}{l}\text { benztropine, trihexyphenidyl, } \\
\text { amantadine, diphenhydramine }\end{array}$ \\
\hline Residence & - private residence \\
& - nursing home \\
& other institutional facility \\
& homeless \\
\hline
\end{tabular}

conventional neuroleptic medication, (b) therapy was discontinued, or (c) September 30, 1998, whichever came first. Medical records were reviewed to verify case or control status, to evaluate the rate of misclassification between cases and controls, and to collect demographic data not available electronically. 


\begin{tabular}{|c|c|c|c|}
\hline & Total & Cases & Controls \\
\hline Neuroleptic Users & 3,683 & 160 & 3,523 \\
\hline $\begin{array}{l}\text { Excluded subjects based } \\
\text { on presence of ICD-9 code }\end{array}$ & 401 & 30 & 371 \\
\hline Charts not available & 69 & 69 & - \\
\hline Remaining Subjects & 3,213 & 61 & 3,152 \\
\hline Randomly selected controls & 659 & - & 659 \\
\hline Abstracted subjects & 375 & 61 & 314 \\
\hline $\begin{array}{l}\text { Excluded subjects after } \\
\text { chart abstraction }\end{array}$ & 148 & 13 & 135 \\
\hline Misclassified subjects & 25 & 6 & 19 \\
\hline $\begin{array}{l}\text { Subjects remaining for } \\
\text { final analysis }\end{array}$ & 202 & 42 & 160 \\
\hline
\end{tabular}

\begin{tabular}{lcc}
\hline TABLE 4 & $\begin{array}{c}\text { Demographic Characteristics } \\
\text { of Cases and Controls }\end{array}$ \\
\hline Characteristic & $\begin{array}{c}\text { Cases (\%) } \\
n=42\end{array}$ & $\begin{array}{c}\text { Control (\%) } \\
n=160\end{array}$ \\
& $51 / 29-76$ & $49 / 25-81$ \\
& $11(26)$ & $58(36)$ \\
Age (mean/range) & $25(62)$ & $79(49)$ \\
$24-44$ & $6(14)$ & $23(15)$ \\
$45-64$ & & \\
$65-84$ & $36(86)$ & $150(94)$ \\
\hline Gender & $6(14)$ & $10(6)$ \\
Male & & \\
Female & $38(91)$ & $121(76)$ \\
Race & $1(2)$ & $25(16)$ \\
Caucasian & $3(7)$ & $6(3)$ \\
African American & 0 & $5(3)$ \\
Hispanic & 0 & $3(2)$ \\
Asian/Pacific Islander & & \\
Native American & & $124(78)$ \\
\hline Residency & $11(7)$ \\
Private residence & $26(62)$ & $8(5)$ \\
Nursing home & $4(8)$ & $17(10)$ \\
Other institutional care & $6(12.5)$ & \\
Homeless & $6(12.5)$ & \\
\hline
\end{tabular}

\section{Exclusionary Criteria for Cases and Control}

There are many diseases that may cause symptoms similar to tardive dyskinesia. Electronic encounter data for the entire cohort were searched to identify subjects with ICD-9 codes for exclu- sionary diagnosis. The paper medical records of the included study subjects were also searched for evidence of exclusionary diagnosis. The following list of diagnoses was used to exclude subjects: Parkinson's disease, Huntington's disease, Wilson's disease, Sydenham's (rheumatoid) chorea, systemic lupus erythematosis, thyrotoxicosis or hyperthyroidism, heavy metal poisoning, Hallervorden-Spatz disease of iron metabolism, SchönleinHenoch purpura, multiple sclerosis, quadriplegic paralysis, and Lou Gehrig's disease.

\section{Data Collection}

Data were collected using the electronic medical record as well as the paper medical record. The electronic record was used to obtain neuroleptic drug exposure, the presence of exclusionary diagnosis, the presence of a diagnosis for tardive dyskinesia, the number of clinic visits, number of hospitalizations, total hospital days, and select demographic data (Table 2). The electronic data were also used to identify other risk factors for tardive dyskinesia such as psychiatric diagnosis, anti-Parkinson drug use, and other drugs that may cause tardive dyskinesia. Data on the use of antiParkinson medication were collected, since these medications are often used to treat acute extrapyramidal symptoms, and those who experience extrapyramidal symptoms are at greater risk of developing tardive dyskinesia. The paper medical record was abstracted to obtain a history of tobacco, alcohol, and illicit drug use, the subject's primary residence, and comorbid diseases.

\section{Data Analysis}

Data were analyzed using Intercooled Stata 6.0 for Windows. ${ }^{21}$ Categorical data were evaluated using the Pearson's Chi Square test. Continuous variables were evaluated using the Student $t$-test. Differences were considered statistically significant at the $P \leq 0.05$ level. The relative risk was estimated by the odds ratio for the association of tardive dyskinesia and neuroleptic drug exposure using unconditional logistic regression. Logistic regression analysis was also performed to control simultaneously for potential confounding factors.

\section{Justification of Sample Size and Power Calculations}

Approximately 44,000 veterans are served by the VA-PSHCS; of those, approximately 3,700 (8\%) received neuroleptic medications between January 1, 1995, and December 31, 1998.22 Using the method described by Schlesselman, ${ }^{23}$ we estimated that 45 cases and 135 controls would be needed to achieve $80 \%$ power $(B=0.2)$, to detect a minimum relative risk of 3.5 , with a ratio of controls to cases of 3:1 and significance level of $\alpha=0.05$. This relative risk was considered adequate to signal a need for further research based on the findings of the Tollefson and Jeste studies, both of which determined the relative risk of tardive dyskinesia in haloperidol users to be approximately 4 times greater than in users of either olanzapine or risperidone. ${ }^{19,24}$ 


\section{Results}

A total of 3,683 subjects used neuroleptic medications between January 1, 1996, and December 31, 1998. A total of 401 subjects-30 cases and 371 controls-had an ICD-9 code for an exclusionary diagnosis. The ICD-9 code for tardive dyskinesia was present in 130 of the remaining subjects. Using SPSS 8.0 for Windows, 659 (20\%) controls were randomly selected from the 3,152 eligible controls. The paper medical charts were not available for 69 cases, so those cases were excluded. Chart reviews were performed on the remaining cases $(\mathrm{n}=61)$. Approximately 5 times as many control charts were abstracted to account for exclusions and to obtain a 3:1 ratio of controls to cases. Three hundred seventy-five charts were reviewed, 61 cases and 314 controls. Thirteen cases $(3.5 \%)$ were excluded because they were not receiving a neuroleptic medication prior to the date of diagnosis for tardive dyskinesia. One hundred thirty-five controls (43\%) were excluded for not being active patients of the VA-PSHCS or because they did not receive more than a one-month supply of neuroleptic medication during the study period. Chart abstraction revealed that misclassification of tardive dyskinesia diagnosis occurred in 19 (5\%) controls and 6 (10\%) TD cases. There were 202 subjects for the final analysis, 42 cases and 160 controls (Table 3).

The demographic characteristics of the case and control groups are presented in Table 4. There was no difference in mean age between the case (TD) group (51; range 29-76) and the control group (49; range 25-81). Since there were no cases in the Asian/Pacific Islander or Native American race categories, race was controlled for Caucasian and non-Caucasian in the final analysis. There were a greater number of Caucasian subjects than nonCaucasian subjects in the case (TD) group (91\%) compared to the control group $(76 \%)$. There was no difference in the proportion of males to females between the two groups. Table 5 summarizes the psychiatric and other comorbid diseases between cases and controls. A larger proportion of controls had depression, bipolar disorder, diabetes mellitus, and hypertension. Table 6 summarizes the neuroleptic drug exposure in the case (TD) and control groups. There was no difference in proportion of atypical and conventional users in the two groups. A larger proportion of TD cases received anti-Parkinson medications than controls (69\% and 31\%, respectively). More controls received other medications that may cause tardive dyskinesia than TD cases (34\% and 19\%, respectively).

No significant difference was found in the risk of tardive dyskinesia between atypical and conventional neuroleptic users (Table 7). After adjusting for other covariates, there was still no significant difference in risk of tardive dyskinesia. We found that users of conventional neuroleptic medications were 1.02 (95\% CI: 0.0.4652.232) times as likely to have a diagnosis for tardive dyskinesia as users of atypical neuroleptic medications after adjusting for age, gender, race, and other covariates (Table 8). Subjects with schizophrenia, schizoaffective disorder, and use of anti-Parkinson drugs

\begin{tabular}{|c|c|c|}
\hline Disease & $\begin{array}{c}\text { Cases (\%) } \\
n=42\end{array}$ & $\begin{array}{c}\text { Controls (\%) } \\
n=160\end{array}$ \\
\hline \multicolumn{3}{|l|}{ Psychiatric Diseases } \\
\hline Schizophrenia & $19(45)$ & $57(36)$ \\
\hline Schizoaffective disorder & $18(43)$ & $22(14)$ \\
\hline Depression & $1(2)$ & $61(38)$ \\
\hline Bipolar disorder & $5(12)$ & $32(20)$ \\
\hline PTSD* & $9(21)$ & $63(39)$ \\
\hline Psychosis NOS & $1(2)$ & $5(3)$ \\
\hline Organic brain dysfunction & $5(12)$ & $19(12)$ \\
\hline \multicolumn{3}{|l|}{ Comorbid Diseases } \\
\hline Diabetes mellitus & $2(5)$ & $32(20)$ \\
\hline Hypertension & $8(19)$ & $58(36)$ \\
\hline GI disorders & $7(17)$ & $31(19)$ \\
\hline Hyperlipidemia & 0 & $1(1)$ \\
\hline Seizure disorders & 0 & $3(2)$ \\
\hline $\mathrm{CAD} \dagger / C V D \dagger \dagger$ & $4(10)$ & $27(17)$ \\
\hline COPD\&/Asthma & $3(7)$ & $22(14)$ \\
\hline BPH \| & $2(5)$ & $11(7)$ \\
\hline Migraine headache & 0 & $5(3)$ \\
\hline Peripheral vascular disease & $2(5)$ & $8(5)$ \\
\hline
\end{tabular}

* Post-traumatic stress disorder

$\dagger$ Coronary artery disease

†† Cerebrovascular disease

$\S$ Chronic obstructive pulmonary disease

II Benign prostatic hypertrophy

\section{TABLE $6 \longdiv { \text { Summary of Drug Exposure } }$ in Cases and Controls}

\begin{tabular}{lccc}
\hline Drug Type & $\begin{array}{c}\text { Cases (\%) } \\
n=42\end{array}$ & $\begin{array}{c}\text { Controls (\%) } \\
\boldsymbol{n}=\mathbf{1 6 0}\end{array}$ & $\begin{array}{c}\text { Significance } \\
\text { (P value) }\end{array}$ \\
\hline $\begin{array}{l}\text { Neuroleptic } \\
\begin{array}{l}\text { Atypical } \\
\text { Conventional }\end{array}\end{array}$ & $\begin{array}{l}72(45) \\
\text { 23(55) }\end{array}$ & $88(55)$ & $\begin{array}{c}\text { ns } \\
\text { ns }\end{array}$ \\
\hline $\begin{array}{l}\text { Anti-Parkinson drug } \\
\text { Other medication that }\end{array}$ & $8(19)$ & $54(34)$ & $(0.03)$ \\
$\begin{array}{l}\text { may cause tardive } \\
\text { dyskinesia }\end{array}$ & & & \\
\hline
\end{tabular}

were at increased risk of having a tardive dyskinesia diagnosis. None of the comorbidities listed in Table 5 was a significant predictor of the outcome, tardive dyskinesia. Schizophrenia and schizoaffective disorder were significant predictors of TD. 


\begin{tabular}{lcc}
\hline TABLE 7 & \multicolumn{2}{l}{$\begin{array}{l}\text { Unadjusted Relative Risk of } \\
\text { Tardive Dyskinesia Following } \\
\text { Use of Neuroleptic }\end{array}$} \\
\hline Neuroleptic & Odds ratio & $95 \%$ Confidence Interval \\
\hline Atypical (reference) & - & - \\
\hline Conventional & 1.289 & $0.711-2.337$ \\
\hline
\end{tabular}

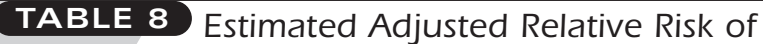 Tardive Dyskinesia Following Use of Neuroleptic Medication}

\begin{tabular}{lcc}
\hline Covariate & Odds Ratio & $\begin{array}{c}95 \% \text { Confidence } \\
\text { Interval }\end{array}$ \\
\hline
\end{tabular}

Atypical neuroleptic

\begin{tabular}{lcc} 
(reference) & - & - \\
\hline Conventional neuroleptic & 1.02 & $0.465-2.232$ \\
\hline Non-white race & 0.44 & $0.167-1.153$ \\
\hline
\end{tabular}

Age

\begin{tabular}{lcc} 
45-64 & 1.68 & $0.723-3.915$ \\
$65-84$ & 1.14 & $0.336-3.873$ \\
\hline Female & 1.91 & $0.538-6.750$ \\
\hline Schizophrenia & 14.06 & $4.468-44.239$ \\
\hline Schizoaffective disorder & 24.84 & $6.931-89.020$ \\
\hline Depression & 0.40 & $0.121-1.334$ \\
\hline Anti-Parkinson drug use & 2.63 & $1.250-5.542$ \\
\hline
\end{tabular}

\section{Discussion}

There is a perception that users of conventional neuroleptic medications may be at increased risk of developing a diagnosis for tardive dyskinesia compared to users of atypical neuroleptic medications. This study did not find a significant difference in the risk of tardive dyskinesia between atypical and conventional neuroleptic medication users; however, it was only powered to detect a difference in risk of 3.5.

Tollefson found that users of haloperidol were 4.6 times as likely to develop tardive dyskinesia as users of olanzapine. ${ }^{24}$ Another study looking at the risk of tardive dyskinesia between risperidone and haloperidol in elderly patients found that users of haloperidol were 4 times as likely to develop tardive dyskinesia as risperidone users. ${ }^{19}$ There are a few reasons why our results may vary from these studies. First, our study did not exclude prevalent cases of tardive dyskinesia. Also, unlike the Tollefson study, we adjusted the risk of tardive dyskinesia based on age, gender, race, psychi- atric diagnosis, and the use of anti-Parkinson medication Furthermore, we combined all atypical medications into one group and did not have a sample large enough to compare them individually to users of conventional neuroleptics. There is evidence that olanzapine may be less likely than risperidone to cause extrapyramidal side effects. Tran and colleagues in a double-blind study looking at olanzapine versus risperidone in the treatment of schizophrenia and other psychotic disorders found that users of olanzapine had significantly fewer extrapyramidal symptoms than users of risperidone..$^{25}$

Based on the findings of this pilot study, more research is warranted using a larger sample size and a longer period of observation. Incident cases of tardive dyskinesia would be the preferred outcome in future research, and the length of neuroleptic exposure should be adequately defined. If available, Abnormal Involuntary Movement Scale scores should be used to aid in the diagnosis of tardive dyskinesia.

\section{Conclusions}

With the introduction of atypical neuroleptic medications into the marketplace, these medications have become favored due to an apparent lower risk of side effects such as tardive dyskinesia. There is little research describing the societal costs of tardive dyskinesia and the loss in quality of life experienced by those with TD. Atypical medications, on average, cost 20 times the amount of conventional medications but are being prescribed more and more with the presumption that they decrease the occurrence of tardive dyskinesia. Among patients with a diagnosis of TD, we found the same incidence of use of atypical neuroleptics as conventional neuroleptics. This finding may complicate the use of pharmacoeconomic studies used to determine if the quality-of-life years gained by using the atypical neuroleptic medications offsets the excess direct (drug) cost of the atypical neuroleptics.

\section{DISCLOSURES}

Funding for this research was provided by the Seattle Veterans Administration/ University of Washington Epidemiology, Research, and Information Center (ERIC). Funding was obtained primarily by authors Donna L. Marshall and Thomas K. Hazlet. None of the authors have financial interests or are affiliated with any company or product mentioned in this article.

Marshall served as principal author of the study. Study concept and design were contributed primarily by Marshall, Hazlet, and author Jacqueline $S$. Gardner. Analysis and interpretation of data were contributed primarily by Marshall and author David K. Blough. Drafting of the manuscript was primarily the work of Marshall. Critical revision of the manuscript was primarily the work of Marshall, Hazlet, and Gardner. Statistical expertise was contributed primarily by Blough and Marshall. Administrative, technical, and/or material support was provided by Gayle Reiber, PhD, and Andy Stergachis, PhD.

\section{ACKNOWLEDGEMENTS}

We would like to thank the Seattle VA/UW Epidemiology, Research, and Information Center for funding this study. We would also like to acknowledge Gayle Reiber, PhD, and Andy Stergachis, PhD, for their contributions to the completion of this study. 


\section{REFERENCES}

1. Casey D. Neuroleptic-induced acute extrapyramidal syndromes and tardive dyskinesia. Psychiatr Clin N Amer. 1993;16:689-710.

2. Andersson C, Chakos M, et al. Emerging roles for novel antipsychotic medications in the treatment of schizophrenia. Psychiatr Clin N Amer. 1998;21:151-79

3. Casey D. Tardive dyskinesia. West J Med. 1990;153:535-41

4. Jeste D, Caligiuri, MP. Tardive dyskinesia. Schizophrenia Bull. 1993;19:30315.

5. Ganzini L, et al. The prevalence of tardive dyskinesia in neuroleptic-treated diabetics. Arch Gen Psychiatry. 1991;48:259-63.

6. Gerber P, Lynd LD. Selective serotonin-reuptake inhibitor-induced movement disorders. Ann Pharmacother. 1998;32:692-98.

7. Riley, MR. Drug Facts and Comparisons. St. Louis, MO: Facts and Comparisons; 2002.

8. Buzan, R. Risperidone-induced tardive dyskinesia. Am J Psychiatry. 1996;153:734-35.

9. Campbell M. Risperidone-induced tardive dyskinesia in first-episode psychotic patients. J Clin Psychopharm. 1999;19:276-77.

10. Carroll N, et al. Chorea and tardive dyskinesia in a patient taking risperidone. J Clin Psychiatry. 1999;60:485-87.

11. Gwinn K, Caviness JN. Risperidone-induced tardive dyskinesia and parkinsonism. Movement Disorders. 1997;12:119-21.

12. Saran B. Risperidone-induced tardive dyskinesia. J Clin Psychiatry. 1998;59:29-30
13. Sue-Hong K, et al. Risperidone-induced tardive dyskinesia. Am J Psychiatry. 1999;156:1290.

14. Woerner M, Sheitman, BB, et al. Tardive dyskinesia induced by risperidone? Am J Psychiatry. 1996;153:843.

15. Addington D, Toew, JA, et al. Risperidone and tardive dyskinesia: a case report. J Clin Psychiatry. 1995;56:484-85.

16. Dunayevich ES, Strakowski SM. Olanzapine-induced tardive dystonia. Am J Psychiatry. 1999;Oct;156:1662.

17. Herran A. Tardive dyskinesia associated with olanzapine. Ann of Intern Med. 1999;131:72.

18. Neumeister A, et al. Tardive dyskinesia with quetiapine. Am J Psychiatry. 1999;156:796-97.

19. Jeste D, et al. Lower incidence of tardive dyskinesia with risperidone compared with haloperidol in older patients. J Am Geriatr Soc. 1999;47:716-19.

20. SPSS 8.0.0 for Windows. SPSS Inc.; 1997.

21. Intercooled Stata 6.0 for Windows 98/95/NT. College Station, TX: Stata Corporation; 1999.

22. Suzuki N. Clin Pharmacy, VA-PSHCS.; 1998.

23. Shlesselman JJ. Sample-size requirements in cohort and case-control studies of disease. Am J Epidemiol. 1974; 99:381-84

24. Tollefson GD, Beasley CM, Tamura RN, et al. Blind, controlled, long-term study of the comparative incidence of treatment-emergent tardive dyskinesia with olanzapine or haloperidol. Am J Psychiatry. 1997;154:1248-54.

25. Tran P, Hamilton SH, Kuntz AJ, et al. Double-blind comparison of olanzapine versus risperidone in the treatment of schizophrenia and other psychotic disorders. J Clin Psychopharm. 1997;17:407-18. 